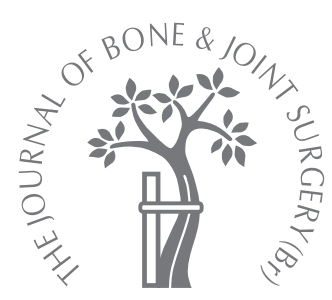

H. Ito,

T. Matsumoto,

H. Yoshitomi,

R. Kakinoki,

T. Nakamura

From Kyoto

University Graduate

School of Medicine,

Kyoto, Japan

\title{
The outcome of peri-operative humeral condylar fractures after total elbow replacement in patients with rheumatoid arthritis
}

\begin{abstract}
We compared the outcome of peri-operative humeral condylar fractures in patients undergoing a Coonrad-Morrey semiconstrained total elbow replacement with that of patients with rheumatoid arthritis undergoing the same procedure without fractures. In a consecutive series of 40 elbows in 33 patients, 13 elbows had a fracture in either condyle peri-operatively, and 27 elbows were intact. The fractured condyle was either fixed internally or excised. We found no statistical difference in the patients' background, such as age, length of follow-up, immobilisation period, Larsen's radiological grade, or Steinbrocker's stage and functional class. There was also no statistical difference between the groups in relation to the Mayo Elbow Performance Score, muscle strength, range of movement, or radiolucency around the implants at a mean of 4.8 years (1.1 to 8.0) followup.
\end{abstract}

We conclude that fractured condyles can be successfully treated with either internal fixation or excision, and cause no harmful effect.

The elbow joint is frequently affected in rheumatoid arthritis (RA). Involvement of the elbow is often progressive and can lead to substantial interference with the activities of daily living. Although endoscopic or open synovectomy is sometimes helpful, total elbow replacement (TER) may be required and has been shown to give satisfactory results with SouterStrathclyde (Stryker Howmedica Osteonics, Allendale, New Jersey), ${ }^{1}$ Kudo (Biomet, Warsaw, Indiana), ${ }^{2,3}$ and Coonrad-Morrey (Zimmer, Warsaw, Indiana)-type implants. ${ }^{4,5}$

Although the Coonrad-Morrey semiconstrained TER has gained widespread acceptance, ${ }^{6,7}$ complications such as condylar fractures may occur. ${ }^{5}$ Peri-articular osteoporosis is common with RA and inevitably makes the bones vulnerable at operation, especially after 'box cutting' in the humerus. Asian people often have small bones, and are particularly susceptible to this intraoperative complication because of the size limitation of the implant, even though an extrasmall implant was introduced in Japan in 2002.

Repair of the condyles is technically demanding following fracture and nonunion in TER. McKee et $\mathrm{al}^{8}$ showed that resection of the humeral condyles does not prejudice either strength or functional outcome, and advised that this could be applied to TER carried out for any reason, including RA. However, this is the only study to show the results of this bold technique. It is desirable that the anatomical structures are retained if possible. The patients of $\mathrm{McKee}$ et $\mathrm{al}^{8}$ had either post-traumatic osteoarthritis or nonunion of fractures of the distal humerus, and the outcome may be different in RA.

In order to restore the anatomy, the fracture fragments should be secured by internal fixation if possible. The purpose of our study was to compare the outcome following peri-operative fracture of the condyles with that when they remained intact in an arthroplasty for RA. We used patient-based outcome measures, including the Mayo Elbow Performance Score, ${ }^{4}$ manual muscle testing, the range of movement and radiological evaluation. We are not aware of any previous account comparing the results of those with peri-operative condylar fractures and those of intact humeral condyles following semiconstrained TER.

\section{Patients and Methods}

This is a retrospective study of a consecutive series of patients who received a CoonradMorrey total elbow prosthesis between June 1998 and May 2005. A total of 40 semiconstrained TERs was carried out on 33 patients with RA, by the senior author (TN) or under his supervision. Two patients died and two were lost to follow-up but their evaluation 
Table I. Demographic data of the two groups

\begin{tabular}{lll}
\hline & Fracture group & Control group \\
\hline Number of fractures & 13 & 27 \\
Mean age in yrs (range) & $64.5(53$ to 74$)$ & 62.5 (38 to 76$)$ \\
Mean follow-up in yrs (range) & $4.68(1.72$ to 7.99$)$ & $4.90(1.05$ to 7.73$)$ \\
Mean Larsen grade (range) & $4.31(2$ to 5$)$ & 4.25 (3 to 5$)$ \\
Mean Steinbrocker stage (range) & $3.46(2$ to 4$)$ & 3.73 (2 to 4$)$ \\
ACR $^{\dagger}$ class & 2.77 (2 to 4$)$ & 2.77 (2 to 3$)$ \\
Mean period of immobilisation (range) & $8.45(5$ to 14$)$ & 8.96 (2 to 15$)$ \\
* not significant & & \\
† ACR, American College of Rheumatology & &
\end{tabular}

Table II. Mayo Elbow Performance Score (MEPS)

\begin{tabular}{lll}
\hline & Fracture group & Control group \\
\hline Pre-operative MEPS & $48.6(30$ to 75$)$ & $49.7(10$ to 70$)$ \\
Pain & $20.8(0$ to 45$)$ & $19.6(0$ to 45$)$ \\
Stability & $3.85(0$ to 10$)$ & $4.23(0$ to 10$)$ \\
Daily function & $8.17(0$ to 25$)$ & $10.26(0$ to 25$)$ \\
Post-operative MEPS & $90.5(75$ to 100$)$ & $90.00(70$ to 100$)$ \\
Pain & $45.0(45$ to 45$)$ & $45.0(45$ to 45$)$ \\
Stability & 10 & 10 \\
Daily function & $17.8(5$ to 25$)$ & $19.5(5$ to 25$)$ \\
\hline * not significant & &
\end{tabular}

Table III. Post-operative manual muscle testing (MMT) and range of movement

\begin{tabular}{lcc}
\hline & Fracture group & Control group $^{*}$ \\
\hline MMT & & \\
$\quad$ Biceps & $4.38(4$ to 5$)$ & $4.56(4$ to 5$)$ \\
$\quad$ Triceps & $3.77(1$ to 5$)$ & $4.28(3$ to 5$)$ \\
The arc of extension/flexion & $108.1(95$ to 145$)$ & $108.4(65$ to 150$)$ \\
Extension $\left(^{\circ}\right)$ & $-35.0(-50$ to -20$)$ & $-30.8(-90$ to 0$)$ \\
Flexion $\left({ }^{\circ}\right)$ & $143.1(130$ to 150$)$ & $139.3(115$ to 150$)$ \\
Pronation $\left({ }^{\circ}\right)$ & $70.0(20$ to 90$)$ & $71.8(0$ to 90$)$ \\
Supination $\left({ }^{\circ}\right)$ & $68.8(30$ to 90$)$ & $74.0(0$ to 90$)$ \\
\hline * not significant & &
\end{tabular}

when last seen has been included. None have been revised. There were 32 women and one man, with a mean age of 63 years (38 to 76 ) at the time of operation. All patients fulfilled the revised criteria of the American College of Rheumatology. ${ }^{9}$

The patients were divided into two groups: those who had a humeral condyle fractured either during, or within two weeks of the operation, and those in whom both condyles were intact. No patient had a condylar fracture more than two weeks after operation. The presence or absence of the fracture was determined radiologically. A fracture was defined as a condyle which had been displaced, removed, or fixed internally. There were 13 elbows with fractures of the condyles (fracture group), and 27 elbows in which they were intact (control group).

Operative technique. The procedure was performed through a Campbell posterior VY approach ${ }^{10}$ in 32 cases and a Tsuge posterolateral approach ${ }^{11}$ in eight. All patients received a cemented Coonrad-Morrey semiconstrained TER. When a condylar fracture occurred, the fragment was removed if the attachable surface was too small to be fixed. If it was large enough for internal fixation it was secured by pinning, wiring or banding with non-absorbable threads.

All patients received prophylactic antibiotics perioperatively and began movement six to 15 days after the operation, regardless of the existence of a fracture. A standard physiotherapy protocol was used.

Assessment. The minimum length of follow-up in both groups was 12 months. The mean follow-up was 4.68 years (1.72 to 7.99 ) in the fracture group and 4.90 years (1.05 to 7.73 ) in the control group. Two of the authors who did not perform the operation (HI and TM) performed a blinded physical and radiological evaluation, and recorded the complete history. Anteroposterior and lateral radiographs were assessed based on a previously described method. ${ }^{12}$ Progressive radiolucency was classified as none, grade $\mathrm{I}(<1$ $\mathrm{mm}$ involving $<50 \%$ of the bone-cement interface), grade II (at least $1 \mathrm{~mm}$ wide involving $<50 \%$ of the interface), grade III ( $>1 \mathrm{~mm}$ involving at least $50 \%$ of the interface), grade IV ( $>2 \mathrm{~mm}$ around the entire interface), or grade V ( $>2 \mathrm{~mm}$ around the entire interface), with movement of the component. ${ }^{12}$ The Mayo Elbow Performance Score was used to document the subjective, objective and functional characteristics before and after the operation. ${ }^{4}$ All patients underwent manual muscle testing of the biceps and the triceps brachii, graded 0 to 5 using the system of Hoppenfold. ${ }^{13}$

Student's $t$-test was used to determine differences between the groups. Ratios between the groups were evaluated by Fisher's exact test with Yate's correction. Significance was set at $\mathrm{p}<0.05$.

\section{Results}

The demographic characteristics of the two groups are presented in Table I. Four further minor procedures were required, one in the fracture group, and three in the control group. In the fracture group a deep infection was treated by open irrigation. In the control group, one triceps insufficiency required reconstruction, one loose bushing was exchanged for a new one and in one patient an ulnar nerve palsy was dealt with by subcutaneous transposition. There was no difference between the two groups with regard to 
Table IV. The presence of radiolucent lines around the components

\begin{tabular}{llllll}
\hline & Fracture group & & \multicolumn{2}{l}{ Control group } \\
\cline { 2 - 3 } $\begin{array}{lllll}\text { Grade of } \\
\text { lucency }\end{array}$ & Humeral component & Ulnar component & & Humeral component & Ulnar component \\
\hline 0 & 13 & 13 & 24 & 26 \\
1 & - & - & - & - \\
2 & - & - & 2 & - \\
3 & - & - & - & - \\
4 & - & - & - & 1 \\
5 & - & - & &
\end{tabular}

Table V. Incidence of fracture related to size of component

\begin{tabular}{lcc}
\hline Size & Number of components & Number of fractures $(\%)$ \\
\hline Regular & 0 & $0(0)$ \\
Small & 26 & $10(38.5)$ \\
Extra-small & 14 & $3(21.4)$ \\
\hline
\end{tabular}

age or the length of follow-up. There was no statistical difference in the pre-operative Larsen radiological grade, ${ }^{14}$ Steinbrocker stage $\mathrm{e}^{15}$ or the American College of Rheumatology functional class. ${ }^{16}$

The results of the Mayo Elbow Performance Score are shown in Table II. There was no statistical difference in all categories of the score between the two groups both before operation or at follow-up. The pre-operative daily function tended to be better in the control group, and this was reflected in a superior post-operative score. Otherwise, the scores were similar in both groups.

Table III shows the manual muscle testing scores on the triceps and the biceps muscles after operation, the arc of flexion-extension and the individual range of movement. There was no significant difference between the two groups. The post-operative manual muscle testing of the triceps was slightly lower in the fracture group because of the patient with triceps insufficiency, but this was not related to the fracture.

The radiological evaluation is shown in Table IV. In the control group, two patients showed grade 2 radiolucency and one a grade 3 radiolucency around the humeral component. There was also one grade 5 radiolucency around an ulnar implant. All the ulnar and humeral components showed no lucencies in the fracture group.

A probable cause of the fractures was that the implants were too big for the humerus of the Asian patients. When the fractures were compared between the sizes of the humeral implant, Table $\mathrm{V}$ shows that the ratio of the fracture to be $38.5 \%$ in the small prostheses, but $21.4 \%$ in the extra-small components. No regular-sized implants were used in these patients. The side operated on did not influence the incidence of fracture.

\section{Discussion}

The various problems which may be encountered following TER have been reviewed by Little et al, ${ }^{6}$ but condylar fractures are one of the most frequently reported intra- operative complications with a Coonrad-Morrey TER, especially in fragile, osteoporotic patients with RA. Indeed, Gill and Morrey ${ }^{5}$ described three condylar fractures in 78 rheumatoid elbows treated with this type of TER $(3.8 \%)$.

In this study we encountered condylar fractures in $32.5 \%$ of patients ( 13 of 40 ), a high ratio. One of the most probable causes is that the implant is too large for small Asian people. This is exemplified by the report by Tsurasaki et $\mathrm{al}^{17}$ that three of seven patients with RA had a condylar fracture. Table V shows that use of the extra-small humeral component reduced the incidence of fractures by almost half. Still smaller sizes are needed, especially in this group of patients.

If a fracture occurs we fix the fragment internally if possible, or else remove it if it is too small. Our results show that with this management the results following fracture are similar to those in which it did not occur. In only two cases was it necessary to excise the condyle, and the results after operation were similar to those in the other patients. McKee et $\mathrm{al}^{8}$ found that excision of both condyles does prejudice elbow function, but extreme caution must be used in adopting this technique. Anatomical restoration is the best treatment if possible.

No benefits in any form have been received or will be received from a commercial party related directly or indirectly to the subject of this article.

\section{References}

1. van der Lugt JC, Geskus RB, Rozing PM. Primary Souter-Strathclyde total elbow prosthesis in rheumatoid arthritis. J Bone Joint Surg [Am] 2004;86-A:465-73.

2. Tanaka N, Kudo $\mathbf{H}$, Iwano $\mathbf{K}$, et al. Kudo total elbow arthroplasty in patients with rheumatoid arthritis: a long-term follow-up study. J Bone Joint Surg [Am] 2001;83A:1506-13.

3. Tanaka N, Sakahashi H, Ishii S, Kudo H. Comparison of two types of ulnar component in type-5 Kudo total elbow arthroplasty in patients with rheumatoid arthritis: a long-term follow-up. J Bone Joint Surg [Br] 2006;88-B:341-4.

4. Morrey BF, Adams RA. Semiconstrained arthroplasty for the treatment of rheumatoid arthritis of the elbow. J Bone Joint Surg [Am] 1992;74-A:479-90.

5. Gill DR, Morrey BF. The Coonrad-Morrey total elbow arthroplasty in patients who have rheumatoid arthritis: a ten to fifteen-year follow-up study. J Bone Joint Surg [Am] 1998;80-A:1327-35.

6. Little CP, Graham AJ, Carr AJ. Total elbow arthroplasty: a systematic review of the literature in the English language until the end of 2003. J Bone Boint Surg [Br] 2005;87-B:437-44.

7. Little CP, Graham AJ, Karatzas G, Woods DA, Carr AJ. Outcomes of total elbow arthroplasty for rheumatoid arthritis: comparative study of three implants. J Bone Joint Surg [Am] 2005;87-A:2439-48.

8. McKee MD, Pugh DM, Richards RR, et al. Effect of humeral condylar resection on strength and functional outcome after semiconstrained total elbow arthroplasty. $J$ Bone Joint Surg [Am] 2003;85-A:802-7.

9. Arnett FC, Edworthy SM, Bloch DA, et al. The American Rheumatism Association 1987 revised criteria for the classification of rheumatoid arthritis. Arthritis Rheum $1988 ; 31: 315-24$ 
10. Campbell WC. Incision for exposure of the elbow joint. Am J Surg 1932;15:65-7.

11. Tsuge K, Murakami T, Yasunaga Y, Kanaujia RR. Arthroplasty of the elbow: twenty years' experience of a new approach. J Bone Joint Surg [Br] 1987;69-B:116-20.

12. Ramsey ML, Adams RA, Morrey BF. Instability of the elbow treated with semiconstrained total elbow arthroplasty. J Bone Joint Surg [Am] 1999;81-A:38-47.

13. Hoppenfold S. Orthopaedic neurology. Philadelphia: JB Lippincott Company, 1999.

14. Larsen A, Dale K, Eek M. Radiographic evaluation of rheumatoid arthritis and related conditions by standard reference films. Acta Radiol Diagn 1977;18:481-91.
15. Steinbrocker $\mathbf{0}$, Traeger $\mathbf{C H}$, Batterman RC. Therapeutic criteria in rheumatoid arthritis. JAMA 1949;140:659-62.

16. Hochberg MC, Chang RW, Dwosh I, et al. The American Rheumatism Association 1991 revised criteria for the classification of global functional status in rheumatoid arthritis. Arthritis Rheum 1992;35:498-502.

17. Tsurasaki T, Kamo H, Maekawa M, et al. Outcome of Coonrad-Morrey total elbow arthroplasty in patients with rheumatoid arthritis. Kyushu-Ryumachi 2005;25:25-9 (in Japanese). 